\title{
Effects of digital game-based learning on students' self- efficacy, motivation, anxiety, and achievements in learning mathematics
}

\author{
Chun-Ming Hung • Iwen Huang • Gwo-Jen Hwang
}

Received: 15 May 2014/Revised: 25 June 2014/Accepted: 1 July 2014/

Published online: 19 July 2014

(C) Beijing Normal University 2014

\begin{abstract}
In this study, a mathematical game-based learning environment is developed on e-books for helping children reduce mathematical anxiety and improve their self-efficacy, motivation, and achievements in learning mathematics. To evaluate the effectiveness of the proposed approach, an experiment was conducted on an elementary school mathematics course. With quasi-experimental research, a total of 69 pupils in three classes were selected as the research subjects. One class was assigned to be experimental group A, another class was experimental group B, and the third was the control group. Each group consisted of 23 students. In the experimental process, the three groups took pre-tests, had experimental instruction, and then took post-tests. The experimental results show that the gamebased e-book learning model effectively promoted the students' learning achievement, self-efficacy, and motivation of mathematics. However, no significant differences were found between the mathematical anxiety ratings of the three groups.
\end{abstract}

Keywords Mathematics anxiety $\cdot$ Game-based learning $\cdot$ Self-efficacy $\cdot$ Learning motivation - Mathematics courses

\section{C.-M. Hung · I. Huang}

Department of Information and Learning Technology, National University of Tainan, No. 33, Sec. 2, Shulin St., T'ai-nan 70005, Taiwan

e-mail: hcm@live.htps.tn.edu.tw

I. Huang

e-mail: huangi@mail.nutn.edu.tw

G.-J. Hwang ( $\square$ )

Graduate Institute of Digital Learning and Education, National Taiwan University of Science and Technology, 43, Sec.4, Keelung Rd., Taipei 106, Taiwan

e-mail: gjhwang.academic@gmail.com 


\section{Background and motivation}

Reducing students' mathematical anxiety, as well as promoting their mathematics self-efficacy, learning motivation, and learning achievement has been recognized as a challenging and important issue (Guilford 1980; Peters 2013; Tapia and Marsh 2004; Vukovic et al. 2013). Educators have tried to cope with this problem by proposing effective teaching strategies or tools in traditional instructional settings. Nevertheless, researchers have found that mathematics remains a forbidding course for many students, so that those students do not try to find the answers when encountering difficulties during the learning process, which seriously affects their learning outcomes (Guilford 1980; Messick 1994).

The advancement and popularity of computers and multimedia technologies have encouraged researchers to develop digital content and systems for mathematics courses. For example, Morales (2005) provided mathematical lessons on a website for engaging student in self-learning, and found that the time for remedial instruction was significantly reduced. Damian and Duguid (2004) reported that the application of multimedia and enjoyable tasks to mathematical concepts could assist students in mathematical learning and help them apply the concepts to daily lives. Nguyen et al. (2006) further indicated that web-based learning allowed students to enhance their mathematical learning attitude and promote their learning motivation, as the interactive and instantly responsive instructions could help students construct knowledge (Steen et al. 2006; Moyer et al. 2008).

On the other hand, Hennessy et al. (2007) indicated that the interactive records of information technology instructions could allow teachers to reflect and improve the curriculum design, as well as cultivate student capabilities of independent thinking and problem solving. Jewitt et al. (2007) regarded that the discussions between teachers and students through technology allowed the curriculum to be closer to students' thinking and further promoted their learning quality. Apparently, technology-supported learning and interactions could cultivate students' construction of mathematical knowledge and enhance their learning motivation.

Many of previous studies have paid attention to the students' motivation in learning mathematics (Hwang et al. 2013; Sins et al. 2008). For example, Legault and Green-Demers (2006) pointed out that lack of learning motivation is the critical problem in the present educational environment. That is, it is important to promote students' learning motivation in order to improve their learning achievement of mathematics. Vansteenkiste et al. (2006) further stated that the way of presenting the learning materials could affect students' learning motivation for mathematics. Several researchers have also addressed similar issues. For example, Alavi et al. (2002) indicated that information technology-enhanced learning could be a solution for promoting students' mathematics learning motivation; Cramer et al. (2008) also indicated that using multimedia to present learning materials could be helpful to children in learning mathematics. Kuo (2007) reported that digital games could provide a learning environment that attracts students' interest in learning mathematics. Several recent studies have also reported that educational computer games have the potential of promoting students' learning motivation, which could result in good learning achievement (Burguillo 2010; Liu and Chu 2010; Dickey 
2010; Houssart and Sams 2008; Huang 2010; Hwang et al. 2013; Sung and Hwang, 2013).

Although previous studies have revealed the effects of multimedia or digital games on promoting students' learning interests and motivations, the impacts of multimedia or digital games on students' self-efficacy of learning mathematics, as well as their learning achievements were seldom investigated; moreover, it has not been reported whether the students' mathematical anxiety can be reduced with those technology-enhanced learning approaches. Students' self-efficacy and deducing anxiety have been recognized as important factors to be considered in educational settings (Li et al. 2011); in particular, in mathematics courses (Schunk 2007). Researchers have pointed out that mathematics anxiety could be one of the key factors that significantly affect students' learning motivation and performance (Clute 1984; Bagaka's 2011). Moreover, students' mathematics self-efficacy could be improved via reducing their mathematics anxiety, which could be helpful to them in improving their learning efficacy (Peters 2013), attitude, and interest (Louis and Mistele 2012). Therefore, it is an important and challenging issue to propose new learning strategies or tools to reduce students' mathematics anxiety and promote their self-efficacy.

In this study, a game-based learning approach is proposed by integrating mathematics content into computer games on mobile devices. Moreover, an experiment has been conducted on an elementary school mathematics course to investigate the following research questions:

1. Can the game-based mathematics learning approach improve the students' selfefficacy in comparison with the conventional technology-enhanced learning approach and traditional instruction?

2. Can the game-based mathematics learning approach promote the students' learning motivation in comparison with the conventional technology-enhanced learning approach and traditional instruction?

3. Can the game-based mathematics learning approach decrease the students' mathematical anxiety in comparison with the conventional technologyenhanced learning approach and traditional instruction?

4. Can the game-based mathematics learning approach improve the students' learning achievement in comparison with the conventional technologyenhanced learning approach and traditional instruction?

\section{Literature review}

Digital Game-based Learning (DGBL) refers to the development and use of computer games for educational purposes (Prensky 2001). A DGBL activity engages students in the process of problem solving or knowledge acquisition when facing the challenges presented by the game (Huang et al. 2010b, 2013). It is expected that, by adding instructional objectives and materials into digital games, 
students' learning motivation would be enhanced because of the challenging and enjoyable nature of the games (Hwang et al. 2012). In recent years, various studies related to DGBL have been reported, revealing the potential of this approach (Hwang et al. 2012; Villalta et al. 2011). For example, the study of Wang and Chen (2010) showed that, with the DGBL approach, students were highly involved in programming activities, which have been recognized as being difficult and boring tasks to most students. Dickey (2011) found that the DGBL approach could promote students' intrinsic motivation. In the meantime, Yien et al. (2011) also reported the positive effect of computer games on students' learning achievement in a nutrition course. The study of Hung et al. (2012) further showed that, with proper design, digital games could improve students' spatial cognition ability. From the literature, it is found that DGBL could be a good approach for improving students' learning motivation and achievement in mathematics.

On the other hand, several studies have reported the benefits of using e-books with wireless communication facilities, while conducting technology-enhanced learning approaches (de Jong and Bus 2002; Janssens and Martin 2009; Siegenthaler et al. 2010; Min et al. 2011). For example, Gil-Rodríguez and Planella-Riberause (2008) indicated that e-books could promote interaction between peers. In addition, both the studies of Stepath (2004) and Shamir and Shlafer (2011) indicated that the use of e-books was beneficial to students' learning outcomes. Based on a large-scale survey, Lee (2012) reported that using e-books to access and execute application programs significantly promoted individuals' perceived usefulness and perceived ease of use in technology-enhanced learning activities. Consequently, in this study, e-books were chosen as the platform of executing the digital games.

\section{Methods}

In this study, a pre-test and post-test-designed quasi-experiment was conducted. The independent variables were the different modes of learning, that is, the DGBL approach on e-books, the technology-enhanced learning approach on e-books, and traditional instruction. The dependent variables were learning achievement, selfefficacy, mathematical motivation, and mathematical anxiety.

\section{Participants}

The participants were 68 fifth graders in three classes of an elementary school. One class with 23 students (11 males and 12 females) was experimental group A, one class with 23 students ( 12 males and 11 females) was experimental group B, and the other class with 23 students (13 males and 10 females) was the control group. To prevent the experimental results being affected by different instructors, the selected classes were taught by the same instructor. The students in experimental group A learned with the DGBL approach on e-books, the ones in experimental group B learned with the technology-enhanced learning approach on e-books, while those in the control group learned with the traditional instruction approach. 


\section{Measuring tools}

The pre-test aimed to evaluate the prior knowledge of the students before the learning activity. It consisted of nine multiple choice, eleven fill-in-the-blank, and five short-answer items with a perfect score of 100. The post-test was developed based on the learning objective of the learning activity. It contained 37 items, including five multiple choice, sixteen fill-in-the-blank, and fifteen short-answer items, also with a perfect score of 100 . Both tests were developed by two teachers who had more than 10 years' experience in teaching Mathematics.

The self-efficacy scale, learning motivation scale, and mathematical anxiety scale originated from the measurement developed by Fennema and Sherman (1977). A five-point rating scheme was employed, where 5 represented "extremely agree" and 1 represented "extremely disagree." The Cronbach's $\alpha$ coefficients for the three sub-scales were $.91, .84$, and .90 , presenting the internal consistency with favorable reliability.

The game-based learning system

The framework was divided into the administrative end and the user end, as shown in Fig 1. The former presented four functions, namely instruction management, material management, synchronization management, and operation management. Instruction management controlled the learning condition of the students; material management was used to compile e-books for instruction; synchronization management presented the students' use of the e-book and the records of their learning condition; while operation management aimed to manage students' assignments. The administrative end could directly compile e-books and remind the user end to install or update the e-books through the cloud learning system.

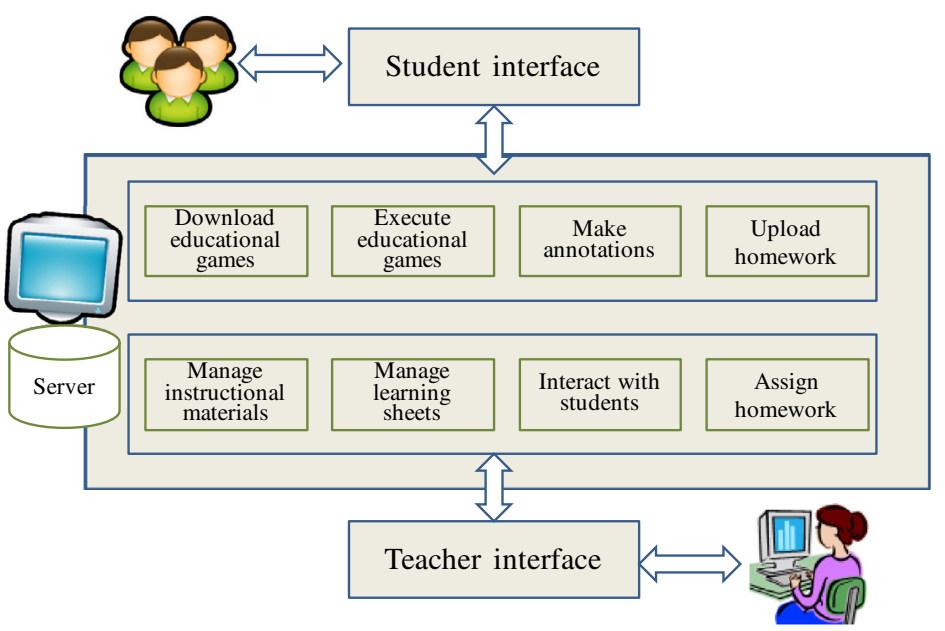

Fig. 1 Mathematics game-based learning environment with e-books 
The user end utilized tablet computers with the Android operation system, which provides four major functions, that is, downloading educational games (APP's), executing educational games, making annotations, and uploading homework. On the other hand, teachers can provide instructional materials and learning sheets, interact with students, and assign homework via the teacher interface.

The unit of "Line symmetry figures" in the elementary mathematics course was designed for the game-based learning model. It included the "Awareness of line symmetry figure-related buildings in life" (a game of selecting the two completely equivalent figures from three), "Knowing axis of symmetry and counting axis of symmetry" (games of a rhombus being folded for up-down or left-right overlapping figures, and an isosceles triangle being folded for left-right overlapping figures), "Knowing point of symmetry, side of symmetry, and angle of symmetry" (a game of line symmetry figures), "Drawing line symmetry figures" (a game of drawing line symmetry figures with grids), and "Exercise" units. Figure 2 shows the learning scenarios of using e-books to play the mathematics games in the classroom.

Figure 3 shows the interface of the "Brick Breaker" game, which was designed for the "Activities for knowing point of symmetry, side of symmetry, and angle of symmetry" unit. When the students broke a specific brick, the learning system showed a question related to the point of symmetry, side of symmetry, and angle of symmetry of a graph. If the students correctly drew the symmetry lines, they would be awarded additional points.
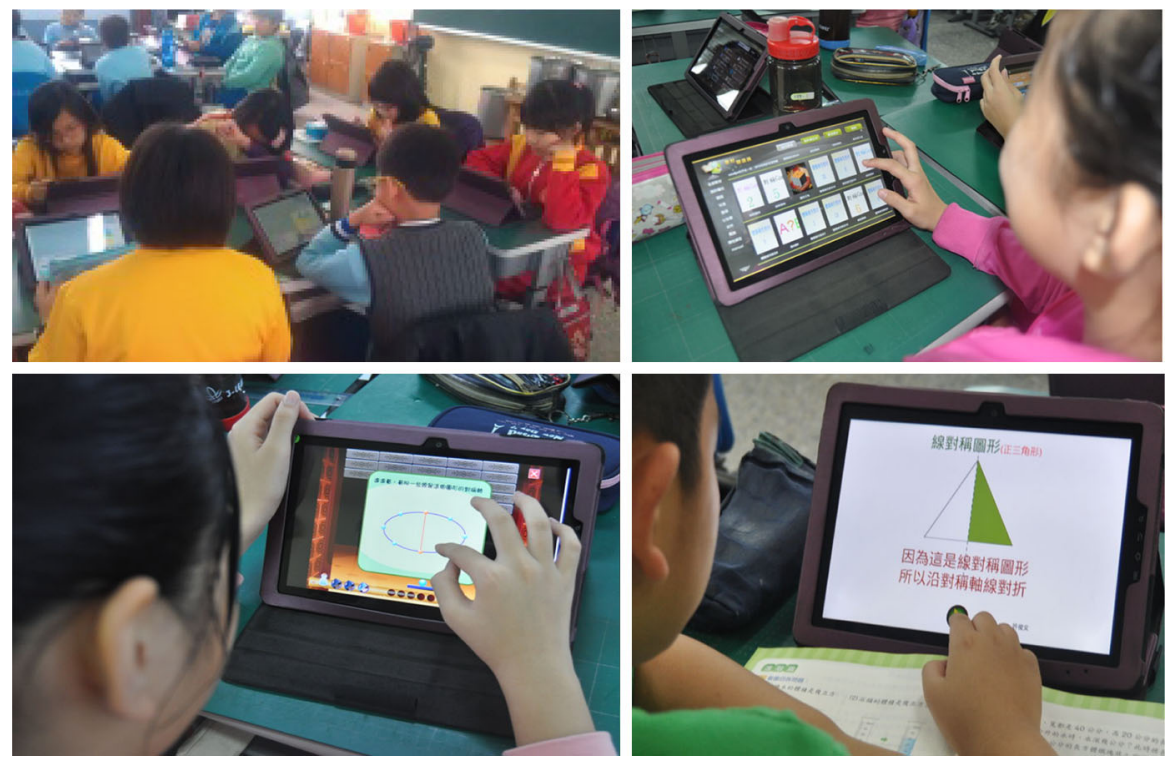

Fig. 2 Learning scenarios of using the mathematics game-based learning system in the classroom 


\section{Experimental procedure}

Figure 4 shows the experimental procedure, which consists of three stages, that is, the pre-test, the introduction to the tools and learning tasks, and the post-test and post-questionnaires.

In the first stage, all of the students took the mathematical course pre-test, and completed the self-efficacy scale, mathematical motivation scale, and mathematical anxiety scale pre-questionnaire. The total time for this stage was $60 \mathrm{~min}$.

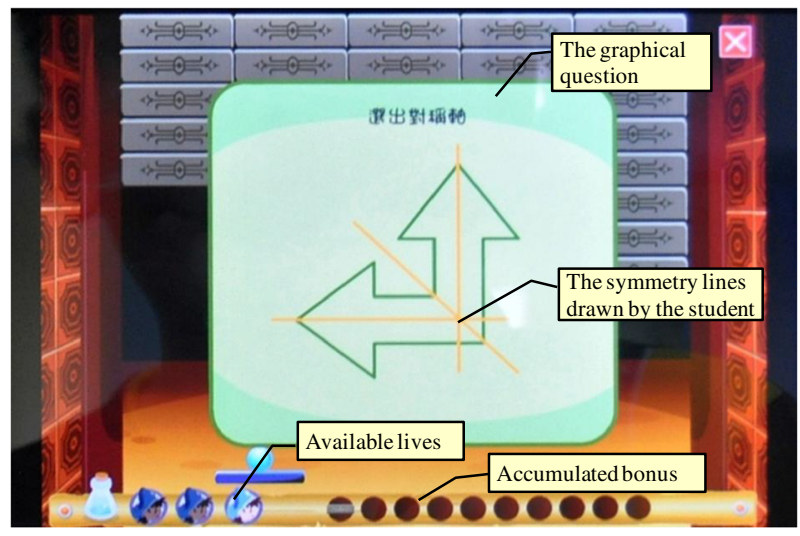

Fig. 3 Interface of the "Brick Breaker" game

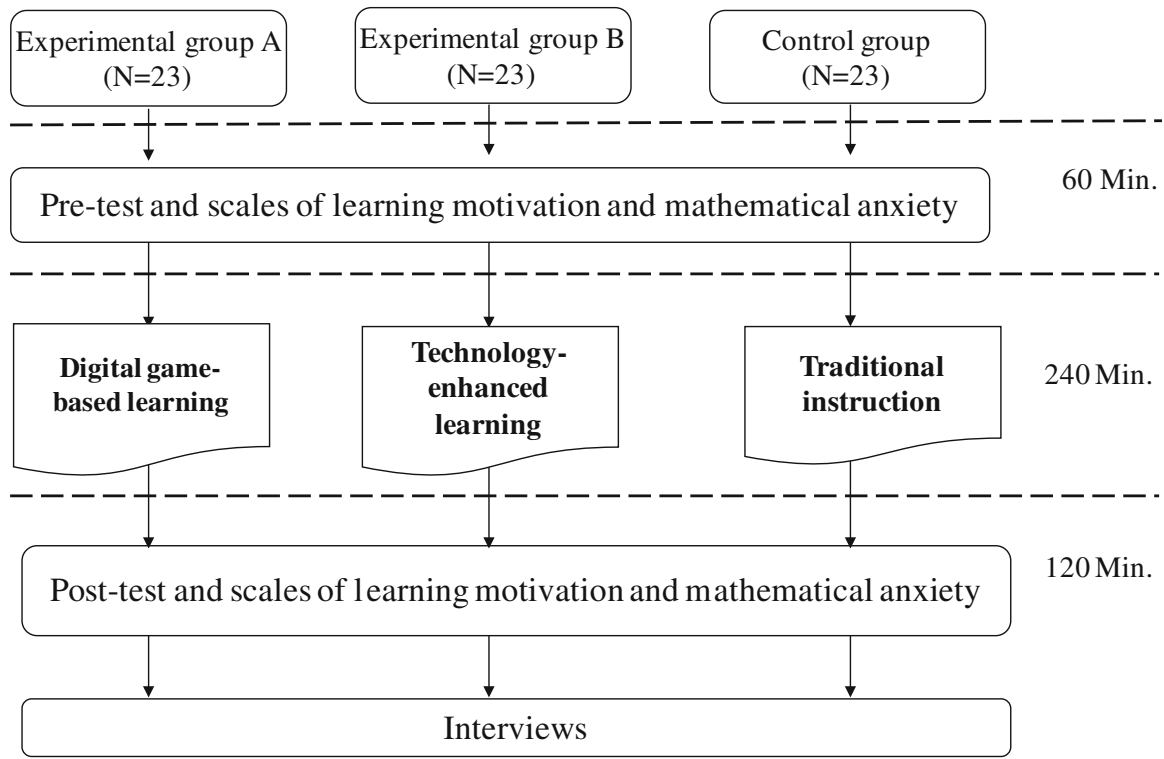

Fig. 4 Experiment procedure 
Following the instruction, a 240-min learning activity was conducted. During the learning activity, the students in experimental group A learned with the game-based learning approach using e-books. The students in experimental group B learned with the learning system on e-books. On the other hand, the students in the control group learned with traditional teacher-directed instruction.

In the final stage, all of the students took the post-test, and completed the selfefficacy scale, mathematical motivation scale, and mathematical anxiety scale postquestionnaire. The total time for this stage was $120 \mathrm{~min}$. Following that, some students in the experimental groups were interviewed by the researchers.

\section{Experimental result}

\section{Self-efficacy}

A pre-questionnaire was used to measure the self-efficacy of the students in learning the target course before the experiment. Table 1 shows the ANOVA result of the pre-questionnaire ratings. It was found that the self-efficacy among the three groups did not appear to be significantly different, with $F=1.38(p>.05)$, implying that the three groups presented equivalent self-efficacy before participating in the learning activity.

After the learning activity, ANCOVA was used to compare the post-questionnaire ratings of the students' self-efficacy by excluding the impacts of the prequestionnaire ratings. Table 2 shows the ANCOVA result. The adjusted means of experimental group A, experimental group B, and the control group were 3.60, 3.67, and 3.27, respectively. Moreover, it was found that the three groups had significant differences on the self-efficacy ratings, with $F=3.67(p<.05)$. The pairwise

Table 1 ANOVA result of the self-efficacy pre-questionnaire ratings of the three groups

\begin{tabular}{llllll}
\hline & Group & $\mathrm{N}$ & Mean & SD & $F$ \\
\hline (EA) & Experimental group A & 23 & 3.53 & .62 & 1.38 \\
$($ EB $)$ & Experimental group B & 23 & 3.19 & .71 & \\
$(\mathrm{C})$ & Control group & 23 & 3.30 & .76 & \\
\hline
\end{tabular}

Table 2 ANCOVA result of the self-efficacy post-questionnaire ratings of the three groups

\begin{tabular}{llllllll}
\hline & Group & N & Mean & SD & Adjusted mean & $F(2,65)$ & $\begin{array}{l}\text { Pairwise } \\
\text { comparisons }\end{array}$ \\
\hline (EA) & Experimental group A & 23 & 3.74 & 0.79 & 3.60 & $3.67 *$ & $($ EA) $>(C)$ \\
(EB) & Experimental group B & 23 & 3.56 & 0.64 & 3.67 & & $($ EB $)>(C)$ \\
$(\mathrm{C})$ & Control group & 23 & 3.24 & 0.82 & 3.27 & \\
\hline
\end{tabular}

$* p<.05$ 
comparisons further showed that both experimental groups A and B outperformed the control group, implying that both DGBL and digital instructional materials on e-books could significantly improve the students' self-efficacy in comparison with the traditional instruction model.

\section{Learning motivation}

Learning motivation has been identified as being an important dimension of evaluating DGBL approaches (Dickey 2011), in particular, for the learning activities in mathematics courses (Messick 1994). In this study, a pre-questionnaire was used to measure the students' motivation of learning mathematics before the experiment. As shown in Table 3, the ANOVA result revealed no significant difference between the learning motivation ratings of the three groups, with $F=1.0(p>.05)$, before participating in the learning activity.

After the learning activity, ANCOVA was used to compare the students' mathematical learning motivation by excluding the impacts of the pre-questionnaire ratings. Table 4 shows the ANCOVA result. The adjusted means of experimental group A, experimental group B, and the control group were 3.78, 3.56, and 3.22, respectively; moreover, the learning motivations of the three groups had significant differences, with $F=3.87(p<.05)$. By applying pairwise comparisons, it was found that experimental group A had significantly higher learning motivation than the control group, while no significant difference was found between the two experimental groups or between experimental group B and the control group, implying that the game-based learning approach could better enhance the students' motivation of learning mathematics than traditional instruction.

Table 3 ANOVA result of the learning motivation pre-questionnaire ratings of the three groups

\begin{tabular}{llllll}
\hline & Group & $\mathrm{N}$ & Mean & SD & $F$ \\
\hline (EA) & Experimental group A & 23 & 3.00 & 0.00 & 1.00 \\
$($ EB) & Experimental group B & 23 & 3.00 & 0.00 & \\
$(\mathrm{C})$ & Control group & 23 & 3.00 & 0.02 & \\
\hline
\end{tabular}

Table 4 ANCOVA result of the learning motivation post-questionnaire ratings of the three groups

\begin{tabular}{llllllll}
\hline & Group & N & Mean & SD & $\begin{array}{l}\text { Adjusted } \\
\text { mean }\end{array}$ & $F(2,65)$ & $\begin{array}{l}\text { Pairwise } \\
\text { comparisons }\end{array}$ \\
\hline (EA) & Experimental group A & 23 & 3.78 & 0.72 & 3.78 & $3.87^{*}$ & $($ EA) $>(C)$ \\
(EB) & Experimental group B & 23 & 3.56 & 0.56 & 3.56 & & \\
(C) & Control group & 23 & 3.23 & 0.72 & 3.22 & \\
& Total number of students & 69 & 3.52 & 0.70 & & \\
\end{tabular}

$* p<.05$ 


\section{Mathematical anxiety}

Mathematical anxiety has been a widely discussed issue for decades (Fennema and Sherman 1977). It has been recognized by educators as an important and challenging issue to decrease the mathematical anxiety of students (Cates and Rhymer 2003). In this study, a pre-questionnaire was used to measure the participants' mathematical anxiety before the experiment. As shown in Table 5, the ANOVA result showed no significant difference between the mathematical anxiety ratings of the three groups, with $F=2.80(p>.05)$, before participating in the learning activity.

After the learning activity, ANCOVA was used to compare the students' mathematical anxiety by excluding the impacts of the pre-questionnaire ratings. Table 6 shows the ANCOVA result. The adjusted means of experimental group A, experimental group B, and the control group were 3.32, 3.46, and 3.54, respectively. The differences between the three groups were not significant, with $F=1.14$ $(p>.05)$.

\section{Learning achievement}

A pre-test was conducted before the experiment to evaluate the basic mathematical knowledge of the students. Table 7 shows the pre-test scores of the three groups.

Table 5 ANOVA result of the mathematical anxiety pre-questionnaire ratings of the three groups

\begin{tabular}{llllll}
\hline & Group & N & Mean & SD & $F$ \\
\hline (EA) & Experimental group A & 23 & 3.44 & .83 & 2.80 \\
$($ EB) & Experimental group B & 23 & 3.76 & .72 & \\
$(\mathrm{C})$ & Control group & 23 & 3.24 & .67 & \\
\hline
\end{tabular}

Table 6 ANCOVA result of the mathematical anxiety post-questionnaire ratings of the three groups

\begin{tabular}{lllllll}
\hline & Group & $\mathrm{N}$ & Mean & SD & Adjusted mean & $F(2,65)$ \\
\hline (EA) & Experimental group A & 23 & 3.29 & 0.70 & 3.32 & 1.14 \\
(EB) & Experimental group B & 23 & 3.65 & 0.74 & 3.46 & \\
(C) & Control group & 23 & 3.37 & 0.73 & 3.54 & \\
\hline
\end{tabular}

Table 7 ANOVA result on the pre-test scores of the three groups

\begin{tabular}{llllll}
\hline & Group & $\mathrm{N}$ & Mean & $\mathrm{SD}$ & $F$ \\
\hline (EA) & Experimental group A & 23 & 75.48 & 16.07 & .50 \\
(EB) & Experimental group B & 23 & 79.35 & 15.55 & \\
$(\mathrm{C})$ & Control group & 23 & 79.48 & 14.48 \\
\hline
\end{tabular}


Table 8 ANCOVA result of the post-test scores of the three groups

\begin{tabular}{llllllll}
\hline & Group & N & Mean & SD & $\begin{array}{l}\text { Adjusted } \\
\text { mean }\end{array}$ & $F(2,65)$ & $\begin{array}{l}\text { Pairwise } \\
\text { comparisons }\end{array}$ \\
\hline (EA) & Experimental group A & 23 & 92.09 & 9.66 & 92.88 & $4.71^{*}$ & $($ EA $)>($ EB $)$ \\
(EB) & Experimental group B & 23 & 87.78 & 8.60 & 87.41 & & $($ EA $)>(C)$ \\
$(C)$ & Control group & 23 & 87.22 & 7.47 & 86.80 & & \\
& Total number of students & 69 & 89.03 & 8.77 & & & \\
\hline
\end{tabular}

$* p<.05$

The ANOVA result shows that the pre-test scores of the three groups did not appear to have significant differences, with $F=.50(p>.05)$, showing that the three groups presented equivalently basic mathematical knowledge before the experiment.

After the experiment, the students' pre-test scores were regarded as the covariance of ANCOVA to exclude the effects of the pre-test on the students' learning achievement. Table 8 shows the ANCOVA result. The adjusted means of experimental group A, experimental group B, and the control group were 92.88, 87.41 , and 86.80 , respectively. The variance $F=4.71 \quad(p<.05)$ indicated the existence of significant differences between the post-test scores of the three groups. From pairwise comparisons, it was found that experimental group A outperformed experimental group B and the control group, while there was no significant difference between experimental group B and the control group.

This result demonstrates that the mathematical game-based learning model could better promote pupils' mathematical learning outcomes than the mobile game learning model and the traditional instruction model.

Interviews with the experimental groups after implementing the mobile gamebased learning model

The students in experimental group A were interviewed after the experiment. The interview questions were related to the effectiveness of the digital game-based mathematics learning with e-books and their willingness of learn with such an approach. From the feedback of the students, it was found that "interesting" and "effective" were the notable features of learning mathematics with the digital games on the e-books.

In terms of "interesting," 15 students mentioned that the game-based learning model was interesting and helpful for learning mathematics without pressure. For example, A3, A4, and A20 stated that, "It is more interesting than traditional instruction. I can operate it and learn better." A4, A8, and A11 stated, "It is more convenient and interesting than traditional instruction. I can learn more new knowledge." A15, A20, and A21 commented, "It is interesting, not boring, without pressure, and it's more fun." A14 mentioned, "I feel relaxed to learn in this way, as I am not interested in raising my hand to ask questions in traditional instruction," 
while A2, A9, A10, and A22 indicated that "The games are interesting. I almost forgot that I was learning mathematics."

In terms of "effective," 12 students mentioned that the DGBL with e-books enabled them to learn in a more effective and efficient way. For example, A23 said that "Presenting the learning content in the digital games on e-books makes mathematics knowledge easy to understand. Those games are helpful to me in learning mathematics." A1, A19, and A23 indicated that "It is great to learn mathematics in this way. We can play mathematical games and make notes about what we do not understand. It is helpful to do that." A2 and A22 mentioned, "After learning with the digital games on e-books, mathematics becomes easier and understandable for me. I can solve more difficult questions now." A22 mentioned that "I prefer lessons with the cloud e-book, as it can help me quickly understand mathematics." A7, A9, A12, and A15 indicated that "It is easy to learn and my mathematics knowledge has improved." A17 and A19 further indicated that "The e-books are handy and convenient for learning."

Furthermore, several students revealed their future desire to use the DGBL approach in mathematics and other courses. For example, A2, A4, A5, A9, A10, A19, and A26 mentioned that "It is fun and I wish to continuously learn mathematics in this way so as to increase my mathematical knowledge." A3, A6, A16, and A17 stated that "It is effective and interesting. I think it can be used for learning science and social studies." A18 commented that "It can be used for learning English." A08 mentioned that "Since it is convenient, I wish it could be applied to every subject."

\section{Discussion and conclusions}

In this study, a DGBL environment for mathematics courses was developed. The students can access the digital mathematical games via e-books with wireless communications. To evaluate the effectiveness of the proposed approach, a learning activity of an elementary school mathematics course was conducted to compare the learning achievements, learning motivations, self-efficacy, and mathematical anxiety of the students who learned with the DGBL approach, conventional e-learning approach, and traditional instruction.

From the experimental results, it was found that both the DGBL group and the e-learning group revealed significantly higher self-efficacy of learning mathematics than the traditional instruction group. As self-efficacy refers to one's belief or expectation in successfully completing some tasks or achieving some specific objectives (Bandura 1988), it is inferred that provision of practice and instant feedback using computer and information technologies (e.g., e-books, wireless networks, and multimedia) is able to encourage students to learn mathematics better. Although the students in the e-learning group did not show significantly higher learning motivation and achievement than the traditional instruction group at the time, their self-efficacy reveals the potential of making progress in learning mathematics in the future. 
On the other hand, it was found that the DGBL group outperformed the other two groups in terms of learning achievements, while the learning achievements of the e-learning group and the traditional instruction group did not have a significant difference. This finding is not obvious, since some previous studies have reported unfavorable results or negative effects of DGBL on students' learning performance (Charsky and Ressler 2011; Pierfy 1977; Randel et al. 1992). In the meantime, it is interesting to find that the students in the game-based learning group showed significantly higher learning motivation than those in the traditional instruction group, while the learning motivations of the e-learning group and the traditional instruction group were not significantly different. From these experimental results and the students' interview feedback, it is inferred that learning with digital games on e-books is able to attract the attention of students and engage them in mathematical practices, which could be the reason why the students had significantly better mathematical achievements than others.

In terms of mathematical anxiety, there were no significant differences between the three groups. Moreover, from the pre-questionnaire and the post-questionnaire ratings, it was found that the mathematical anxiety ratings of both the DGBL group and the e-learning group decreased after the learning activity, while that of the traditional instruction group increased. This implies that computer and information technologies and gaming strategies have good potential for decreasing the mathematical anxiety of students. That is, it is worth developing and utilizing digital mathematics games in the future.

In the future, some improvements can be made to the present gaming model. First, the current digital games are designed for individuals, although the students can communicate with their peers and the teacher. It would be more interesting and effective if the mathematics games were designed for the students to complete gaming missions, as well as learn mathematics collaboratively or competitively (Villalta et al. 2011; Hwang et al. 2012). Second, most mathematical games, including the ones used in this study, do not situate students in authentic learning scenarios that engage them in solving real-world problems with mathematical knowledge. To overcome these drawbacks, we are planning to conduct a project to develop mathematics games that engage students in solving real-world problems collaboratively via mobile devices with wireless communications. Moreover, we also plan to generalize the games by providing an interface that allows researchers and instructors to modify the learning content in the games to meet the needs of different courses.

Acknowledgments This study is supported in part by the National Science Council of the Republic of China under contract numbers NSC 99-2511-S-011-011-MY3 and NSC 101-2511-S-011 -005-MY3.

\section{References}

Alavi, M., George, M. M., \& Yoo, Y. (2002). A comparative study of distributed learning environments on learning outcomes. Information Systems Research, 13(4), 404-415.

Bagaka's, J. G. (2011). The role of teacher characteristics and practices on upper secondary school students' mathematics self-efficacy in Nyanza province of Kenya: A multilevel analysis. International Journal of Science and Mathematics Education, 9(4), 817-842. 
Bandura, A. (1988). Organizational application of social cognitive theory. Australian Journal of Management, 13(2), 275-302.

Burguillo, J. C. (2010). Using game theory and competition-based learning to stimulate student motivation and performance. Computers \& Education, 55(2), 566-575.

Cates, G. L., \& Rhymer, K. N. (2003). Examining the relationship between mathematics anxiety and mathematics performance: an instructional hierarchy perspective. Journal of Behavioral Education, 12(1), 23-34.

Charsky, D., \& Ressler, W. (2011). "Games are made for fun": Lessons on the effects of concept maps in the classroom use of computer games. Computers \& Education, 56(3), 604-615.

Clute, P. S. (1984). Mathematics anxiety, instructional method, and achievement in a survey course in college mathematics. Journal for Research in Mathematics Education, 15(1), 50-58.

Cramer, K., Wyberg, T., \& Leavitt, S. (2008). The role of representations in fraction addition and subtraction. Mathematics Teaching in the Middle School, 13(8), 490-496.

Damian, C., \& Duguid, J. (2004). Searching for wow! picturebooks. ENC Focus: A Magazine for Classroom Innovators, 12, 13.

de Jong, M. T., \& Bus, A. G. (2002). Quality of book-reading matters for emergent readers: An experiment with the same book in a regular or electronic format. Journal of Educational Psychology, 94, 145-155.

Dickey, M. D. (2010). Murder on Grimm Isle: the impact of game narrative design in an educational game-based learning environment. British Journal of Educational Technology,. doi:10.1111/j.14678535.2009.01032.x.

Dickey, M. D. (2011). Murder on Grimm Isle: The impact of game narrative design in an educational game-based learning environment. British Journal of Educational Technology, 42(3), 456-469.

Fennema, E., \& Sherman, J. (1977). Sex-related differences in mathematics achievement, spatial visualization, and affective factors. American Educational Research Journal, 14(1), 51-71.

Gil-Rodríguez, E. P., \& Planella-Ribera, J. (2008). Educational uses of the e-book: An experience in a virtual university context. HCI and Usability for Education and Work, 5298, 55-62.

Guilford, J. P. (1980). Cognitive style: What are they? Educational and Psychological Measurement, 40, $715-735$.

Hennessy, S., Deaney, R., Ruthven, K., \& Winterbottom, M. (2007). Pedagogical strategies for using the interactive whiteboard to foster learner participation in school science. Learning Media and Technology, 32(3), 283-301.

Houssart, J., \& Sams, C. (2008). Developing mathematical reasoning through games of strategy played against the computer. International Journal for Technology in Mathematics Education, 15(2), 59-71.

Huang, W. H. (2010). Evaluating learners' motivational and cognitive processing in an online gamebased learning environment. Computers in Human Behavior, doi:10.1016/j.chb.2010.07.021.

Huang, W. H., Huang, W. Y., \& Tschopp, J. (2010). Sustaining iterative game playing processes in DGBL: The relationship between motivational processing and outcome processing. Computers \& Education, 55(2), 789-797.

Hung, P. H., Hwang, G. J., Lee, Y. H., \& Su, I. H. (2012). A cognitive component analysis approach for developing game-based spatial learning tools. Computers \& Education, 59(2), 762-773.

Hwang, G. J., Sung, H. Y., Hung, C. M., \& Huang, I. (2012a). Development of a personalized educational computer game based on students' learning styles. Educational Technology Research and Development, 60(4), 623-638.

Hwang, G. J., Wu, P. H., \& Chen, C. C. (2012b). An online game approach for improving students' learning performance in web-based problem-solving activities. Computers \& Education, 59(4), 1246-1256.

Hwang, G. J., Sung, H. Y., Hung, C. M., \& Huang, I. (2013a). A learning style perspective to investigate the necessity of developing adaptive learning systems. Educational Technology \& Society, 16(2), 188-197.

Hwang, G. J., Sung, H. Y., Hung, C. M., Yang, L. H., \& Huang, I. (2013b). A knowledge engineering approach to developing educational computer games for improving students' differentiating knowledge. British Journal of Educational Technology, 44(2), 183-196.

Hwang, G. J., Yang, L. H., \& Wang, S. Y. (2013c). A concept map-embedded educational computer game for improving students' learning performance in natural science courses. Computers \& Education, 69(1), 121-130. 
Janssens, G., \& Martin, H. (2009). The feasibility of e-ink readers in distance learning: A field study. International Journal of Interactive Mobile Technologies, 3(3), 38-46.

Jewitt, C., Moss, G., \& Cardini, A. (2007). Pace, interactivity and multimodality in teachers' design of texts for interactive whiteboards in the secondary school classroom. Learning Media and Technology, 32(3), 303-317.

Kuo, M. J. (2007). How does an online game based learning environment promote students' intrinsic motivation for learning natural science and how does it affect their learning outcomes?. In The first IEEE international workshop on digital game and intelligent toy enhanced learning, Jhongli, Taiwan, March 26-28.

Lee, S. (2012). An integrated adoption model for e-books in a mobile environment: Evidence from South Korea. Telematics and Informatics, . doi:10.1016/j.tele.2012.01.006.

Legault, L., \& Green-Demers, I. (2006). Why do high school students lack motivation in the classroom? Toward an understanding of academic amotivation and the role of social support. Journal of Educational Psychology, 98, 567-582.

Li, C. J., Lin, P. C., \& Hsiu, H. L. (2011). The relationships among adult attachment, social self-efficacy, distress self-disclosure, loneliness and depression of college students with romance. Bulletin of Educational Psychology, 43(1), 155-174.

Liu, T. Y., \& Chu, Y. L. (2010). Using ubiquitous games in an English listening and speaking course: Impact on learning outcomes and motivation. Computers \& Education, 55(2), 630-643.

Louis, R. A., \& Mistele, J. M. (2012). The differences in scores and self-efficacy by student gender in mathematics and science. International Journal of Science and Mathematics Education, 10(5), 1163-1190.

Messick, S. (1994). The matter of style: Manifestation of personality in cognition, learning, and teaching. Educational Psychologist, 29(3), 121-136.

Min, S. H., Kim, H. Y., Kwon, Y. J., \& Sohn, S. Y. (2011). Conjoint analysis for improving the e-book reader in the Korean market. Expert Systems with Applications, 38(10), 12923-12929.

Morales, C. R. (2005). Using on-line digital video to augment the teaching of frequency/spatial filtering operations. Computers in Education Journal, 15, 45-52.

Moyer, P. S., Salkind, G., \& Bolyard, J. J. (2008). Virtual manipulatives used by K-8 teachers for mathematics instruction: Considering mathematical, cognitive, and pedagogical fidelity. Contemporary Issues in Technology and Teacher Education, 8(3), 202-218.

Nguyen, D. M., Hsieh, Y. J., \& Allen, G. D. (2006). The impact of web-based assessment and practice on students' mathematics learning attitudes. The Journal of Computer in Mathematics and Science Teaching, 25(3), 251-279.

Peters, M. L. (2013). Examining the relationships among classroom climate, self-efficacy, and achievement in undergraduate mathematics: A multi-level analysis. International Journal of Science and Mathematics Education, 11(2), 459-480.

Pierfy, D. A. (1977). Comparative simulation game research: Stumbling blocks and steppingstones. Simulation \& Games, 8(2), 255-268.

Prensky, M. (2001). Digital game-based learning. New York: McGraw Hill.

Randel, J. M., Morris, B. A., Wetzel, C. D., \& Whitehall, B. V. (1992). The effectiveness of games for educational purposes: A review of recent research. Simulation \& Gaming, 23(3), 261-276.

Schunk, D. H. (2007). Learning theories: An educational perceptive (5th ed.). NJ: Prentice-Hall.

Shamir, A., \& Shlafer, I. (2011). E-books effectiveness in promoting phonological awareness and concept about print: A comparison between children at risk for learning disabilities and typically developing kindergarteners. Computers \& Education, 57(3), 1989-1997.

Siegenthaler, E., Wurtz, P., \& Groner, R. (2010). Improving the usability of e-book readers. Journal of Usability Studies, 6, 25-38.

Sins, P. H. M., van Joolingen, W. R., Savelsbergh, E. R., \& van Hout-Wolters, B. (2008). Motivation and performance within a collaborative computer-based modeling task: Relations between students' achievement goal orientation, self-efficacy, cognitive processing, and achievement. Contemporary Educational Psychology, 33, 58-77.

Steen, K., Brooks, D., \& Lyon, T. (2006). The impact of virtual manipulatives on first grade geometry instruction and learning. Journal of Computers in Mathematics and Science Teaching, 25(4), 373-391.

Stepath, C. M. (2004). Coral reef education and Australian High School Students. (ERIC Documemt Reproduction Service No. ED 491455). 
Sung, H. Y., \& Hwang, G. J. (2013). A collaborative game-based learning approach to improving students' learning performance in science courses. Computers \& Education, 63(1), 43-51.

Tapia, M., \& Marsh, G. E, I. I. (2004). An instrument to measure mathematics attitudes. Academic Exceange Quarterly, 8(2), 16-21.

Vansteenkiste, M., Lens, W., \& Deci, E. L. (2006). Intrinsic versus extrinsic goal contents in selfdetermination theory: Another look at the quality of academic motivation. Educational Psychologist, 41(1), 19-31.

Villalta, M., Gajardo, I., Nussbaum, M., Andreu, J. J., Echeverría, A., \& Plass, J. (2011). Design guidelines for classroom multiplayer presential games (CMPG). Computers \& Education, 57, 2039-2053.

Vukovic, R. K., Kieffer, M. J., Bailey, S. P., \& Harari, R. R. (2013). Mathematics anxiety in young children: Concurrent and longitudinal associations with mathematical performance. Contemporary Educational Psychology, 38(1), 1-10.

Wang, L. C., \& Chen, M. P. (2010). The effects of game strategy and preference-matching on flow experience and programming performance in game-based learning. Innovations in Education and Teaching International, 47(1), 39-52.

Yien, J. M., Hung, C. M., Hwang, G. J., \& Lin, Y. C. (2011). A game-based learning approach to improving students' learning achievements in a nutrition course. Turkish Online Journal of Educational Technology, 10(2), 1-10.

Chun-Ming Hung is a PhD student in the Department of Information and Learning Technology, National University of Tainan, Taiwan. His research interests include digital game-based learning, mobile learning and digital storytelling.

Iwen Huang is an associate professor in the Department of Information and Learning Technology, National University of Tainan, Taiwan. Her research interests include web-based learning, mobile learning and digital storytelling.

Gwo-Jen Hwang is a Chair Professor in the Graduate Institute of Digital Learning and Education, National Taiwan University of Science and Technology, Taiwan. His research interests include mobile and ubiquitous learning, digital game-based learning, artificial intelligence in education, and web-based learning. 